\title{
PUBLIC GOODS GAMES WITH COSTLY SWITCHING FROM A STATUS QUO*
}

\author{
STATÜKODAN SAPMANIN MALIYETLİ OLDUĞU \\ KAMU MALI OYUNLARI
}

Begüm GÜNEY ${ }^{*}$

\begin{abstract}
We apply Guney and Richter's (2016) choice model of costly switching from a status quo to public goods games. We find that non-zero contribution into the public good can be optimal under a status quo contribution level. Moreover, intermediate contribution levels are no longer optimal if the switching cost depends only on the status quo contribution level but not on the contribution level the agent switches to.
\end{abstract}

Keywords: Public Goods Game; Contribution; Switching Cost.

JEL classification: D00; D01; D03; C72

Özet

Guney ve Richter'in (2016), kişinin statükodan başka bir alternatif seçmesinin kişiye maliyetli olabileceğini öneren seçim davranışını kamu malı oyunlarına uygulamaktayız. Bir statüko katkı düzeyi varlığında, kamu malına sıfırdan farklı bir katkı yapmanın optimal olabileceğini göstermekteyiz. Ayrıca göstermekteyiz ki, eğer sapma maliyeti statüko dışında kalan alternatiflere bağlı olmayıp sadece statükoya bağlı olursa, kişinin kamu malına statüko veya sıfır dışında kalan ara değerlerde katkı yapması optimal olmaz.

Anahtar Kelimler: Kamu Malı Oyunu; Katkı; Sapma Maliyeti.

JEL sınıflandırması: D00; D01; D03; C72

* The author acknowledges financial support by the Scientific and Technological Research Council of Turkey, Project No: 113K370.

** Ass. Prof. Dr., Ozyegin University, Faculty of Business, Nişantepe Mah. Orman Sk. No: 34-36 Çekmeköy İstanbul, Orcid Id: orcid.org/0000-0002-8638-6295, e-posta: begum.guney@ozyegin.edu.tr 


\section{Introduction}

Experimental and empirical evidence establishes that choices are influenced by status quos and a variety of theoretical models are proposed to explain status quo effects. One recent theory is by Guney and Richter ${ }^{1}$. They extend the classical choice framework by incorporating an exogenously given status quo alternative into the standard choice problem and axiomatically characterize a status quo-based choice procedure. In a choice problem with a status quo, each alternative different from the status quo is associated with a non-negative cost that can vary depending upon which alternative the agent switches to and from, whereas staying with the status quo itself is associated with zero cost. Guney and Richter ${ }^{2}$ interpret this non-negative cost as a switching cost that the agent incurs if he moves away from the status quo. In their model, the agent with a status quo chooses the available alternative whose utility net of the switching cost is the highest. Our purpose in the present paper is to apply Guney and Richter's ${ }^{3}$ status quo-based choice model to a public goods game.

In the standard public goods game, each agent in a group of $\mathrm{N}$ individuals decides on a division of his money between a private account that brings a return only to himself and a public account that brings a return to everyone in the group. According to the standard utility maximization theory, it is rational to invest $\$ 0$ in the public account. However, this is in contrast to experimental outcomes where individuals are frequently observed to invest money in the public account. ${ }^{4,5,6,7}$

In the present paper, we show that non-zero contribution levels can be most preferred under a non-zero contribution level that serves as a status quo. This application also emphasizes the importance of a switching cost function that varies depending upon which alternative the agent switches to and from. This is because intermediate contribution levels can no longer be optimal when the switching cost depends only on the status quo alternative that the agent switches from but not on the alternative he switches to. Note that in this case contributing either zero or the status quo level (or both) may still be most preferred though.

Given the choice model employed in this application relies on status quos, one might very well question the reasonableness of considering a status quo in a public goods game setting. Status quos are not unlikely to appear in such settings. For example, a social norm such as a suggested

1 Guney, B., Richter, M. (2016). Choice and Games with Switching Costs, https://drive.google.com/file/ d/148r7XPBEFcgPO3w_D-RVSdVnFB2G7IhN/view? usp=sharing, (Erişim Tarihi: 5.12.2017)

2 Guney, B., Richter, M., 2016, 1-60.

3 Guney, B., Richter, M., 2016, 1-60.

4 Marwell, G., Ames, R. (1979). Experiments on the Provision of Public Goods i: Resources, Interest, Group Size, and the Free-Rider Problem, American Journal of Sociology, 84: 1334-1360.

5 Marwell, G., Ames, R. (1980). Experiments on the Provision of Public Goods ii: Provision Points, Stakes, Experience, and the Free-Rider Problem, American Journal of Sociology, 85: 926-937.

6 Marwell, G., Ames, R. (1981). Economists Free Ride, Does Anyone Else? Experiments on the Provision of Public Goods, Journal of Public Economics, 15: 295-310.

7 Schneider, F., Pommerehne, W. (1981). Free Riding and Collective Action: An Experiment in Public Microeconomics," The Quarterly Journal of Economics, 96: 689-704. 
contribution amount printed on a fundraising flyer or an agent's earlier contribution level can very well serve as a status quo contribution level in the current public goods game. Earlier research in the literature also realizes the possibility of status quos in these games. Messer et al. ${ }^{8}$ introduce a status quo in their public goods game experiment through an "opt-out" mechanism: Each agent's endowment of $\$ 1$ is put directly into the public account and the agent is asked to decide about how much of that money to refund to his private account with the rest remaining in the public account. ${ }^{9}$ Hence, the presence of the status quo is associated with a mechanism where the agent should opt-out to contribute less than $\$ 1$ while the absence of a status quo is associated with the mechanism where the agent needs to opt-in to contribute a positive amount into the public account. ${ }^{10}$ The contribution rates are observed to be higher than those in the standard public goods games when a status quo contribution level is introduced ${ }^{11}$ and our findings in this paper are in line with these experimental results.

Note that status quos are not the only possible explanation behind the non-zero contribution rates observed in public good experiments. For instance, theories of altruism, fairness, and reciprocity are some prominent explanations provided in the literature ${ }^{12,13,14,15}$ However, our aim in the present paper is not to compare such theories with Guney and Richter's ${ }^{16}$ model in their ability to explain non-zero contribution rates. This is beyond the scope of the paper. Instead, we would like to draw attention to the ability of status quos in explaining non-zero contributions in a public goods game setting, which hasn't been done earlier in the theoretical literature.

The rest of the paper is organized as follows. In Section 2, we introduce our set up and present our results. Concluding remarks are given in Section 3. All proofs are presented in Appendix.

\section{The Model and Results}

In the standard public goods game, each agent in a group of $\mathrm{N}$ individuals divides his money between a public account and his private account. Each dollar the agent keeps in his private account

8 Messer, K.D. et al. (2007). New Hope for the Voluntary Contributions Mechanism: The Effects of Context, Journal of Public Economics, 91: 1783-1799.

9 This mechanism could work with any other status quo level $\mathrm{z} \in(0,1)$ when contributions greater or less than $\mathrm{z}$ are allowed.

10 Indeed, such opt-in and opt-out mechanisms are used in organ donation programs in real life (Johnson, E. J., Goldstein, D. (2003). Do Defaults Save Lives?, Science, 302: 1338-1339).

11 Messer, K. D. et al., 2007, 1783-1799.

12 Andreoni, J. (1989). Giving with Impure Altruism: Applications to Charity and Ricardian Equivalence, Journal of Political Economy, 97: 1447-1458.

13 Charness, G., Rabin, M. (2002). Understanding Social Preferences with Simple Tests, The Quarterly Journal of Economics, 117: 817-869.

14 Rabin, M. (1993). Incorporating Fairness into Game Theory and Economics, The American Economic Review, 83: 1281-1302.

15 Dufwenberg, M., Kirchsteiger, G. (2004). A Theory of Sequential Reciprocity, Games and Economic Behavior, 47: 268-298.

16 Guney, B., Richter, M., 2016, 1-60. 
brings him a return of $\$ 1$. Each dollar collected in the public account brings every agent a return of $\$ \alpha$, where $1>\alpha>1 / N .^{17}$

We now apply our theory to a continuous public goods game where there is an exogenous status quo contribution level. We concentrate only on pure actions. Without loss of generality, assume each agent has $\$ 1$ and decides on a division of his $\$ 1$ between a private and a public account. The vector $x=\left(x_{1}, x_{2}, \ldots, x_{N}\right)$, where $x_{i} \in[0,1]$ for all $\mathrm{i}$, denotes all agents' contributions (out of their own $\$ 1)$ to the public account. Agent i derives the following status quo-free utility that he maximizes in the absence of a status quo:

$U_{i}(x)=1-x_{i}+\alpha \sum_{j=1}^{n} x_{j}$, where $1 / N<\alpha<1$.

Moreover, as modeled in Guney and Richter ${ }^{18}$, we suppose that each agent $\mathrm{i}$ has a lower semi continuous function $D_{i}:[0,1] \times[0,1] \rightarrow \mathbb{R}_{+}$with $D_{i}(x, x)=0$ for any $x \in[0,1] \cdot{ }^{19}$ In line with Guney and Richters ${ }^{20}$ interpretation, we interpret $D_{i}\left(x_{i}, z\right)$ as the switching cost agent $i$ incurs if he makes a contribution of $\$ x_{i}$ into the public account while his status quo contribution level is $\$ z$. In such a choice problem with a status quo $\mathrm{z}$, agent $\mathrm{i}$ chooses the contribution level $x_{i}$ that maximizes the following:

$U_{i}(x)-D_{i}\left(x_{i}, z\right)$

Note that the existence of a status quo contribution level $\$ z$ does not necessarily imply that it is best for the agent to contribute $\$ z$ into the public good. If the cost of switching from the status quo $\$ \mathrm{z}$ is low, then the agent would benefit from contributing less than $\$ \mathrm{z}$, say $\$ x_{i}$ where $x_{i}<\mathrm{z}$, as this would save him money of $\$\left(z-x_{i}-D_{i}\left(x_{i}, z\right)\right)$.

The following result shows that non-zero contribution levels are possible in the presence of a status quo and hence, contributions in that case are (weakly) greater than those made in the absence of a status quo.

Proposition 2.1 Given a switching cost function $D_{i}$ and a status quo contribution level $\mathrm{z} \leq 1$, agent $\mathrm{i}$ has a maximally preferred contribution level and any such contribution level is in the range $[0, z]$. Moreover, for any value $y$ in this range, there exists a switching cost function that realizes $\mathrm{y}$ as the agent's optimal contribution level.

The proposition above is consistent with the observed increase in contribution rates due to the introduction of a status quo (via an opt-out mechanism rather than an opt-in one). ${ }^{21},{ }^{22}$

17 The literature calls $\alpha$ the marginal per capita return (MPCR). It must be between $1 / \mathrm{N}$ and 1 for a conflict between private interests and group interests to exist.

18 Guney, B., Richter, M., 2016, 1-60.

19 For the axiomatic characterization and features of the observed behavior of this model, please see Guney, B., Richter, M., 2016, 1-60. Here, we only concentrate on its application to public goods games.

20 Guney, B., Richter, M., 2016, 1-60.

21 Messer, K. D. et al., 2007, 1783-1799.

22 Johnson, E. J., Goldstein, D., 2003, 1338-1339 
In order to emphasize the importance of a switching cost function that depends on both the alternative the agent switches to and from, we will now focus on the following specific class of cost functions:

$D_{i}(x, z)=\psi_{i}(z)>0$ for all $\mathrm{z}$ and $\mathrm{x}$ that are different.

Additionally, we will assume $D_{i}(z, z)=0$ still holds. An agent with such a $\mathrm{D}$ function incurs a positive switching cost whenever he makes a contribution different than his status quo $z$, and moreover, the amount of the cost is the same, regardless of the amount $\mathrm{x}$ he switches to. We call such a cost function "status quo specific". This special form of the cost function is first introduced in Masatlioglu and $\mathrm{Ok}^{23}$

Our next result shows that an agent with a status quo specific switching cost function does not contribute to the public account at intermediate levels. The optimal behavior for him is to contribute either nothing or the amount that serves as the status quo or both.

Proposition 2.2 Given a switching cost function $D_{i}$ that is status quo specific and a status quo contribution level $\mathrm{z} \leq 1$, agent is preferred contribution level exists and is either 0 or $\mathrm{z}$ or both. ${ }^{24}$

An intuition for the above proposition is as follows. $\psi_{i}(z)$ represents the switching cost for moving from the default $\mathrm{z}$ to another contribution level. Given that the agent will pay a flat cost whenever he switches to another contribution level, the best contribution level to switch to among all non-status quo contribution levels is 0 if the agent wants to move away from his status quo at all. 0 is the optimal contribution level if the benefit of switching from $z$ to 0 , which is $(1-\alpha) z$ is greater than the switching cost $\psi_{i}(z)$. If the benefit is less than the cost, then staying with the status quo $\mathrm{z}$ is optimal. Finally, 0 and $\mathrm{z}$ are both optimal if the benefit exactly equals the switching cost.

\section{Conclusion}

This paper presents a novel application of Guney and Richter's ${ }^{25}$ choice model into public goods games. The results show that status quo-based choice can be an explanation for non-zero contribution rates that are frequently observed in experimental studies. If the switching cost depends on both the status quo contribution level and the contribution level the agent switches to (as in Guney and Richter ${ }^{26}$ ), then intermediate levels of contribution can be optimal. However, if the switching cost depends only on the status quo contribution level (as in Masatlioglu and

23 Masatlioglu, Y., Ok, E. (2005). Rational Choice with Status Quo Bias, Journal of Economic Theory, 121:1-29.

24 This proposition holds also when $\psi_{-} \mathrm{i}(\mathrm{z}) \geq 0$.

25 Guney, B., Richter, M., 2016, 1-60.

26 Guney, B., Richter, M., 2016, 1-60. 
$\mathrm{Ok}^{27}$ ), then optimal contribution level is either the status quo or nothing (or both). This stresses the importance of the general switching cost function studied in Guney and Richter ${ }^{28}$.

As already mentioned in the paper, there are also other models that can also explain non-zero cooperation rates in public goods games and given that the focus of the present paper is on applying Guney and Richter's ${ }^{29}$ model, comparing it with other possible theoretical explanations is beyond the scope of this work. However, one interesting direction to explore as a future work could be to compare all these models both theoretically and experimentally to see which one(s) can better explain the observed behavior in public goods games.

\section{References}

ANDREONI, J. (1989). Giving with Impure Altruism: Applications to Charity and Ricardian Equivalence, Journal of Political Economy, 97: 1447-1458.

CHARNESS, G., Rabin, M. (2002). Understanding Social Preferences with Simple Tests, The Quarterly Journal of Economics, 117: 817-869.

DUFWENBERG, M., Kirchsteiger, G. (2004). A Theory of Sequential Reciprocity, Games and Economic Behavior, 47: 268-298.

GUNEY, B., Richter, M. (2016). Choice and Games with Switching Costs, https://drive.google.com/file/ d/148r7XPBEFcgPO3w_D-RVSdVnFB2G7IhN/view? usp=sharing, (Erişim Tarihi: 5.12.2017).

JOHNSON, E. J., Goldstein, D. (2003). Do Defaults Save Lives?, Science, 302: 1338-1339.

MARWELL, G., Ames, R. (1979). Experiments on the Provision of Public Goods i: Resources, Interest, Group Size, and the Free-Rider Problem, American Journal of Sociology, 84: 1334-1360.

MARWELL, G., Ames, R. (1980). Experiments on the Provision of Public Goods ii: Provision Points, Stakes, Experience, and the Free-Rider Problem, American Journal of Sociology, 85: 926-937.

MARWELL, G., Ames, R. (1981). Economists Free Ride, Does Anyone Else? Experiments on the Provision of Public Goods, Journal of Public Economics, 15: 295-310.

MASATLIOGLU, Y., Ok, E. (2005). Rational Choice with Status Quo Bias, Journal of Economic Theory, 121: 1-29.

MESSER, K. D., Zarghamee, H., Kaiser, H. M., Schulze, W. D. (2007). New Hope for the Voluntary Contributions Mechanism: The Effects of Context, Journal of Public Economics, 91: 1783-1799.

RABIN, M. (1993). Incorporating Fairness into Game Theory and Economics, The American Economic Review, 83: 1281-1302

SCHNEIDER, F., Pommerehne, W. (1981). Free Riding and Collective Action: An Experiment in Public Microeconomics, The Quarterly Journal of Economics, 96: 689-704.

27 Masatlioglu, Y., Ok, E., 2005, 1-29.

28 Guney, B., Richter, M., 2016, 1-60.

29 Guney, B., Richter, M., 2016, 1-60. 


\section{Appendix}

\section{Proof of Proposition 2.I}

By lower semi-continuity of $D_{i}$ and continuity of $U_{i}$, for any given reference point, agent is net utility is upper semi-continuous over a compact set, and therefore an optimal (not necessarily unique) contribution level exists.

From now on, we will write $U_{i}\left(x_{i} x_{-i}\right)$ instead of $U_{i}(x)$ where $x=\left(x_{1}, \ldots, x_{i}, \ldots, x_{N}\right)$.

For any contribution level $y$ that is greater than $z, U_{i}\left(z x_{-i}\right)>U_{i}\left(y x_{-i}\right)$ and $D_{i}(y, z) \geq D_{i}(z, z)$ and therefore $U_{i}\left(z x_{-i}\right)-D_{i}(z, z)>U_{i}\left(y x_{-i}\right)-D_{i}(y, z)$. As a result, an agent with the status quo $\mathrm{z}$ never makes a contribution more than $\mathrm{z}$.

To prove the "moreover" part, take any contribution level y in the range $[0, \mathrm{z}]$ and define the cost function as follows:

$$
D(x, z)=\left\{\begin{array}{lc}
\frac{(1-\alpha)(z-y)}{2} & \text { if } x=y \\
0 & \text { if } x=z \\
1 & \text { otherwise }
\end{array}\right.
$$

Note that the cost function is lower semi-continuous. The following shows that the net utility from contributing $\mathrm{y}$ is greater than that of contributing $\mathrm{z}$ :

$$
\begin{aligned}
U_{i}\left(y x_{-i}\right)-D_{i}(y, z) & =U_{i}\left(y x_{-i}\right)-\frac{(1-\alpha)(z-y)}{2} \\
= & U_{i}\left(z x_{-i}\right)+(1-\alpha)(z-y)-\frac{(1-\alpha)(z-y)}{2} \\
= & U_{i}\left(z x_{-i}\right)+\frac{(1-\alpha)(z-y)}{2}>U_{i}\left(z x_{-i}\right)=U_{i}\left(z x_{-i}\right)-D_{i}(z, z)
\end{aligned}
$$

Additionally, among all other contribution levels, as the switching cost is fixed, the most preferred contribution level is 0 .

Furthermore,

$$
\begin{aligned}
& U_{i}\left(y x_{-i}\right)-D_{i}(y, z)=U_{i}\left(y x_{-i}\right)-\frac{(1-\alpha)(z-y)}{2} \\
& =U_{i}\left(0 x_{-i}\right)-(1-\alpha) y-\frac{(1-\alpha) z}{2}+\frac{(1-\alpha) y}{2} \\
& =U_{i}\left(0 x_{-i}\right)-\frac{(1-\alpha)(z+y)}{2} \geq U_{i}\left(0 x_{-i}\right)-(1-\alpha)>U_{i}\left(0 x_{-i}\right)-1=U_{i}\left(0 x_{-i}\right)-D_{i}(0, z)
\end{aligned}
$$

Therefore, y i s optimal.

\section{Proof of Proposition 2.2}

Existence has already been established in a more general setting in Proposition 2.1.

To show that an intermediate value in the interval $(0, z)$ cannot be an optimal level, take any y such that $y \in(0, z)$. Then, 
$U_{i}\left(y x_{-i}\right)-D_{i}(y, z)=U_{i}\left(y x_{-i}\right)-\psi_{i}(z)=U_{i}\left(0 x_{-i}\right)-(1-\alpha) y-\psi_{i}(z)<U_{i}\left(0 x_{-i}\right)-$ $\psi_{i}(z)=U_{i}\left(0 x_{-i}\right)-D_{i}(0, z)$

Therefore, y cannot be optimal.

Now, consider the difference between the net utilities from contributing $\mathrm{z}$ and 0 :

$U_{i}\left(z x_{-i}\right)-D_{i}(z, z)-U_{i}\left(0 x_{-i}\right)+\psi_{i}(z)$

$=U_{i}\left(0 x_{-i}\right)-(1-\alpha) z-U_{i}\left(0 x_{-i}\right)+\psi_{i}(z)$

$=-(1-\alpha) z+\psi_{i}(z)$

If $\psi_{i}(z)<(1-\alpha) z$, then 0 is the optimal contribution level.

If $\psi_{i}(z)>(1-\alpha) z$, then $\mathrm{z}$ is the optimal contribution level.

If $\psi_{i}(z)=(1-\alpha) z$, then both 0 and $z$ are optimal. 